DOI: 10.17805/trudy.2017.3.3

\title{
СОЦИАЛЬНО-ПСИХОЛОГИЧЕСКИЙ ТРЕНИНГ КАК СРЕДСТВО ФОРМИРОВАНИЯ ПРОФЕССИОНАЛЬНОЙ КОМПЕТЕНТНОСТИ ГОСУДАРСТВЕННЫХ ГРАЖДАНСКИХ СЛУЖАЩИХ
}

\author{
Д. А. Горский \\ Московский гуманитарный университет
}

\begin{abstract}
Аннотация: Встатье рассмотрены актуальные проблемы использования социальнопсихологического тренинга как ключевого средства формирования и развития профессиональной компетентности государственных гражданских служащих. Охарактеризованы основные подходы к понятию профессиональной компетентности и средства ее развития. Предложены способы применения компонентов «ситуационного» подхода к профессиональной компетентности для целей социально-психологического тренинга.

Ключевые слова: социально-психологический тренинг; профессиональная компетентность; государственная гражданская служба; государственный служащий; организационная психология
\end{abstract}

\section{SOCIO-PSYCHOLOGICAL TRAINING AS A MEANS OF FORMING PROFESSIONAL COMPETENCE OF PUBLIC SERVANTS}

\author{
D. A. Gorskiy \\ Moscow University for the Humanities
}

\begin{abstract}
The article deals with current issues of using socio-psychological training as a key means of forming and developing the professional competence of public servants. The main approaches to the concept of professional competence and means of its development are characterized. The article also suggests ways of using the components of the «situational» approach to professional competence for the purposes of socio-psychological training.

Keywords: socio-psychological training; professional competence; public service; public servant; organizational psychology

Проблема профессиональной компетентности уже не одно десятилетие находится в центре внимания исследователей и практиков бизнеса, некоммерческой сферы, государственной службы, науки и образования. Наиболее остро данная проблема стоит перед руководителями и сотрудниками государственной гражданской службы, так как от их профессиональной компетентности зависит не только качество оказываемых государственных услуг, но и отношение граждан страны к государственной службе и власти в целом. Необходимо отметить, что на сегодняшний день в науке и практической деятельности не сложилось единого подхо-
\end{abstract}


да к определению понятия «профессиональная компетентность». Вместе с тем, без четкого понимания сути и содержания профессиональной компетентности, наличия ясных критериев ее оценки и определения факторов эффективности ее применения практически невозможно понять, насколько она действительно сформирована у каждого конкретного представителя государственной гражданской службы.

Анализ исследований в данной сфере позволяет выделить три основных подхода к пониманию профессиональной компетентности, которые условно можно назвать поведенческим, личностным и ситуативным. Представители «поведенческого» подхода (Д. МакКлелланд, Л. Спенсер, С. Спенсер, Е. И. Барышникова) понимают профессиональную компетентность как своеобразный набор способностей, базовых «автоматизмов», устойчивых стереотипных поведенческих действий, которые помогают исполнителю успешно решать стоящие перед ним рабочие задачи. Соответственно, для формирования и совершенствования профессиональной компетентности, по мнению представителей данного подхода, необходимо выделить ключевые аспекты работы, описать поведенческие действия, необходимые для ее выполнения и предложить критерии успешности этих действий для эффективного выполнения работы (Спенсер Л., Спенсер С., 2005; Барышникова, 2013).

Представители «личностного» подхода (И. Адизес, Р. Бояцис, Дж. Равен) определяют профессиональную компетентность через личность исполнителя, ее мотивы, установки, саморефлексию, степень интеграции с социальным окружением, реализуемые социальные роли. Соответственно, формирование и развитие профессиональной компетентности невозможно без учета системы ценностных ориентаций, аттитьюдов, отношений с социальным окружением исполнителей работы (Адизес, 2007; Бояцис, 2008; Равен, 2002). Британский психолог Дж. Равен, например, прямо заявляет, что оценивать навыки и способности в отрыве от ценностей попросту бессмысленно, а потому оценка приоритетов человека должна стать ключевой задачей формирования и развития профессиональной компетентности сотрудников (Равен, 2014).

Представители «ситуационного» подхода (Г. Гарднер, К. Альбрехт) определяют профессиональную компетентность как способность индивида быстро реагировать на стимулы рабочей среды и успешно адаптироваться к ее изменениям (Альбрехт, 2011). В этом смысле целью формирования и развития профессиональной компетентности становится выделение особенностей современной динамичной рабочей среды и поиск релевантных средств, помогающих успешной адаптации исполнителя к ее условиям. Так, исследование, охватившее 91 страну, проведенное в 2015 г. совместно специалистами Всемирного экономического форума 
(ВЭФ) и Бостонской консалтинговой группы (БКГ), позволило выделить 16 ключевых «компонентов» (знаний, умений и навыков), важных для абсолютно всех сотрудников в современных условиях деловой среды. Все выделенные компоненты исследователи разделили на три категории, каждая из которых играет важную роль в способности индивида адаптироваться к постоянно меняющимся условиям современной рабочей среды: базовые навыки, компетенции, черты характера. Базовые навыки определяют способность человека успешно решать повседневные рабочие задачи. К ним исследователи отнесли навыки чтения, письма и математики, естественно-научные знания, грамотность в сфере финансов и информационно-компьютерных технологий, а также культурную и гражданскую грамотность. Собственно компетенции определяют способность индивида эффективно решать сложные рабочие задачи. К ним относятся творческое и критическое мышление, коммуникативные навыки, умение работать в команде. Не менее важным фактором для адаптации к условиям рабочей среды оказывается и характер человека. Важными чертами характера, позволяющими эффективно приспосабливаться к изменениям, специалисты признали любознательность, инициативность, настойчивость, способность адаптироваться, лидерские качества, а также социальную и культурную осведомленность (Горелова, 2015: Электр. ресурс).

Представляется, что «ситуационный» подход к определению профессиональной компетентности на сегодняшний день является более продуктивным, чем «поведенческий» или личностный. Во-первых, ситуационный подход позволяет учитывать сложность, динамичность и изменчивость современной рабочей среды. Во-вторых, ситуационный подход указывает на необходимый минимум конкретных навыков, который может понадобиться индивиду для успешной адаптации к возможным изменениям среды. В-третьих, ситуационный подход предлагает релевантный инструментарий, который, с одной стороны, позволяет диагностировать наличие необходимых для успешной работы компетенций, а, с другой стороны, предлагает конкретные инструменты развития этих компетенций. B-четвертых, в ситуационном подходе учитывается такая важная переменная современного мира, как культурное многообразие: гендерное, возрастное, национальное. В-пятых, ситуационный подход в некоторой степени обращен в недалекое будущее и дает возможность уже сейчас учитывать технические, технологические и информационные тренды эры наступающей четвертой промышленной революции.

Таким образом, когда речь заходит о формировании и развитии профессиональной компетентности у государственных гражданских служащих, целесообразно учитывать достижения и наработки «ситуационного» подхода. На начальном этапе необходимо оценить базовый уровень 
знаний и способностей служащих, которые могут помочь им успешно решать рутинные, стандартизированные рабочие задачи. Затем следует диагностировать степень способности и готовности государственных гражданских служащих к решению нестандартных, инновационных задач и проблем. И, наконец, необходимо определить наличие у служащих определенных черт характера, необходимых для успешной адаптации.

После процедуры оценки трех указанных компонентов потребуется подобрать релевантные средства формирования и развития профессиональных компетенций. Организационная психология в настоящее время располагает внушительным арсеналом подобных средств. По нашему мнению, данные средства условно можно разделить на несколько важных групп: организационные (корпоративные), управленческие и психологические средства. К организационным (корпоративным) средствам формирования и развития профессиональных компетенций относятся инструменты, имеющие отношение к совершенствованию организационной среды и условий ее функционирования. Прежде всего, это такие широко распространенные инструменты, как совершенствование корпоративной культуры; формирование релевантных программ усиления вовлеченности (приверженности) сотрудников организационным целям и ценностям; совершенствование программ мотивации и стимулирования труда сотрудников; создание культуры самообучающейся организации, совершенствование механизмов обучения и развития сотрудников; широкое внедрение передовых информационных технологий повышения профессиональной компетентности (компьютерные имитаторы деятельности, игровые стимуляторы); проведение на регулярной основе конкурсов профессионального мастерства, мастер-классов и воркшопов (в том числе с приглашением сторонних для организации экспертов); стимулирование сотрудников к добровольному созданию кружков качества и обмена опытом профессиональной деятельности; инвестиции в кадровый резерв; создание систем управления талантами (перспективными сотрудниками).

К управленческим средствам формирования и развития профессиональных компетенций можно отнести такие инструменты, как формирование управленческих команд на основе взаимодополняющих навыков; совершенствование стиля руководства и лидерства менеджеров организации на всех уровнях организационной иерархии; совершенствование руководителями системы принятия и реализации управленческих решений; развитие культуры делегирования полномочий и вовлечения сотрудников в процессы принятия управленческих решений; коррекция распространенных управленческих «патологий», таких как маятниковые, дублирующие или демотивирующие управленческие решения, микро- 
менедмент; формирование лидерских навыков у рядовых исполнителей; изменение отношения к функции контроля через развитие инициативности, самостоятельности и ответственности исполнителей; предоставление исполнителям возможности самостоятельно выбирать пути достижения поставленных целей; регулярные мотивационные речи (выступления) руководителей перед рабочими коллективами; демонстрация руководителем исполнителям высокого уровня развития профессиональной компетентности с помощью личного примера.

Перечисленные выше организационные (корпоративные) и управленческие средства являются чрезвычайно важными для формирования и совершенствования профессиональной компетентности. Более того, они существуют в неразрывной связи и взаимозависимости, и их эффективность целиком и полностью зависит от согласованности, упорядоченности и непротиворечивости. Однако, как справедливо отмечает Дж. Равен, проблема компетентности/ некомпетентности состоит не в том, что людям не хватает каких-либо технических (экспертных) знаний (и именно этот предполагаемый «дефицит» знаний люди пытаются ликвидировать прежде всего), а в том, что человек оказывается неспособным «заняться вопросами, которые лежат за пределами отдельной области знаний специалиста» (Равен, 2014: 170).

В этом контексте хотелось бы более подробно остановиться на психологических средствах формирования и развития профессиональной компетентности сотрудников, так как многие организации уделяют им незаслуженно мало внимания, особенно по сравнению с организационными (корпоративными) и управленческими. Во многом это связано со сложностью организации и реализации их на практике; отсутствием необходимых специальных знаний и навыков у руководителей и сотрудников организаций; недостаточностью информации об особенностях и эффективности данных инструментов; опасениями и страхами потенциальных участников социально-психологических тренингов и иных форматов; встречающимися негативными представлениями и отзывами о них и некоторыми другими причинами.

K психологическим средствам формирования и развития профессиональной компетентности могут относиться, например, психодиагностические методики, средства психогигиены и психокоррекции, инструменты психологии творческой деятельности, методы психологического консультирования, социально-психологические инструменты развития малых групп, а также другие психологические средства и методы.

При использовании психологических средств формирования и развития профессиональных компетенций стоит обратить внимание на ряд их особенностей. Во-первых, они сосредоточены преимущественно не 
на технических (экспертных) компетенциях, а на индивидуальном вкладе сотрудников в саморазвитие и развитие профессиональной сферы (по Дж. Равену). Во-вторых, они имеют комплексный характер и включают в себя одновременно как инструменты диагностики, так и инструменты коррекции и совершенствования компетенций. В-третьих, их использование сталкивается с определенными проблемами методологического характера, связанными с разработкой и валидизацией релевантных критериев оценки развития конкретных компонентов профессиональной компетентности.

Психологические средства формирования и развития профессиональных компетенций имеют отношение как к отдельным индивидам (и в этом смысле мы можем говорить об индивидуально-психологических инструментах), так и к группам людей в организации (социальнопсихологические инструменты) и затрагивают основные проблемы психологии личности и психологии малых групп. Следовательно, при использовании данных средств руководителю необходимо уметь учитывать большое количество разных переменных. Например, специфику групповой динамики, потенциальные конфликты в малой группе, распределение власти, групповые нормы и правила, индивидуальные установки и аттитюды, стереотипы, особенности восприятия, индивидуальные способы обработки информации людьми, мотивационные типы членов коллектива и другие переменные.

Граница между индивидуально-психологическими и социальнопсихологическими средствами развития профессиональных компетенций имеет весьма условный характер. Основное различие между двумя группами средств - количественное. В случае индивидуально-психологических средств мы говорим о личном влиянии субъекта развития профессиональных компетенций (руководителя, коллеги, приглашенного эксперта, психолога организации) на конкретного индивида. В случае социальнопсихологических средств речь идет о развитии профессиональных компетенций одновременно у группы людей, собранных в одном ограниченном физическомпространстве.Основнымииндивидуально-психологическими средствами формирования и развития профессиональных компетенций являются индивидуальные беседы, коучинг, менторство, супервизорство, ассессмент-центры и др. К социально-психологическим средствам можно отнести тренинги, мероприятия по командообразованию, школы профессионального мастерства.

Наша практика работы с организациями показывает, что социальнопсихологический тренинг является одним из наиболее эффективных инструментов повышения профессиональной компетентности. Прежде всего, он позволяет задействовать (и одновременно развивать) три основные 
сферы человеческой личности: когнитивную, аффективную и конативную. Участвуя в тренинге, люди не только предпринимают определенные интеллектуальные усилия (когнитивная сфера), но и испытывают и пытаются совладать с захватывающими их эмоциями (аффективная сфера), а также осуществляют какие-либо конкретные поведенческие действия (конативная сфера). Таким образом, социально-психологический тренинг дает возможность участникам посредством решения индивидуальных и групповых задач совершенствовать интеллектуальные навыки; посредством осознания собственных эмоций, анализа причин их возникновения и действий по их регулированию развивать навыки эмоционального интеллекта; посредством выполнения совместных практических заданий с другими участниками тренинга, участия в мозговых штурмах и групповых дискуссиях совершенствовать свой рабочий поведенческий репертуар.

Помимо этого, социально-психологический тренинг позволяет адекватно оценивать, формировать и развивать основные компоненты профессиональной компетентности,выделенныеБостонскойконсалтинговой группой (БКГ). Прежде всего, компетенции, позволяющие решать сложные рабочие задачи, а также некоторые черты характера, принципиально важные для возможности адаптации к условиям рабочей среды. Рассмотрим данный тезис на примере авторского социально-психологического тренинга «Развитие навыков клиентоориентированности государственных гражданских служащих - руководителей подразделений и специалистов ФНС России». Данный тренинг был разработан и апробирован автором в 2013 г. в рамках мероприятий Федеральной целевой программы «Развитие единой государственной системы регистрации прав и кадастрового учета недвижимости», реализация которой первоначально была рассчитана в период до 2016 г. Уже в середине 2016 г. в связи с серьезными положительными результатами, полученными при реализации программы социально-психологического тренинга, Федеральная целевая программа была продлена до 2019 г. (Горский, 2013; Дивненко, Горский, 2017).

На текущий момент участниками тренинга стали более 4000 сотрудников Федеральной налоговой службы России, осуществляющих профессиональную деятельность во всех регионах РФ - от Калининграда до Владивостока и вовлеченных в непосредственное общение с налогоплательщиками. Обучаясь качественной работе с налогоплательщиками, участники тренинга проигрывают и анализируют совместно с группой и тренером потенциальные рабочие ситуации: участвуют во «встрече» с типичными, сложными и потенциально конфликтными клиентами, устанавливают контакт с ними, определяют их психотип, ведут с ними переговоры, выясняют их явные и скрытые запросы, учатся реагировать на возражения, т. е. формируют такие компетенции как умение общать- 
ся, умение работать в команде, инициативность, настойчивость и способность адаптироваться.

Личные беседы с тренерами, участвующими в реализации Федеральной целевой программы, получение от них профессиональных рекомендаций и советов, запрос и получение обратной связи от других участников социально-психологического тренинга, обмен знаниями и опытом работы с коллегами, просмотр и анализ видеозаписей личного участия в разыгрывании ситуаций профессионального общения с партнерами способствуют развитию таких профессиональных компетенций, как критическое мышление, способность к личной и профессиональной рефлексии, стрессоустойчивость, инициативность и ответственность.

На формирование профессиональных компетенций также влияют групповые упражнения на совместную деятельность, разборы практических ситуаций (кейсов), специальным образом организуемые и/или спонтанно возникающие дискуссии между участниками тренинга, ведущие к необходимости формировать собственную точку зрения на неоднозначные и проблемные ситуации, подбирать аргументы в ее защиту, отстаивать их перед аудиторией, пытаться выслушать, понять и проанализировать контраргументы оппонентов, найти в них «здравое зерно» и противоречия, корректно их опровергнуть.

Помимо этого, участники тренинга учатся реагировать на новые, неожиданные, нетипичные ситуации, которые предлагает им тренер, самостоятельно принимать по ним обоснованные решения, предлагать их аудитории, рисковать, брать на себя инициативу в случаях неизвестности и неопределенности, отвечать за их последствия. Так формируются такие компетенции, как способность к критическому и творческому мышлению, способность адаптироваться, лидерские качества.

Ну и, наконец, сотрудники ФНС, участвующие в тренинге, являются представителями различных культурных групп (возрастных, гендерных, этнических, профессиональных, географических, субкультурных и пр.) и носителями разных, порой несовпадающих (или даже несовместимых) ценностей. Соответственно, совместная работа на тренинге помогает повышать культурную и гражданскую грамотность, являющуюся важной составляющей базового компонента профессиональной компетентности.

Особо хочется отметить современные информационно-коммуникационные технологии, которые позволяют расширить границы и возможности социально-психологического тренинга. Уже стало общим местом использование в тренинговом процессе видеозаписи упражнений, которые выполняют участники, с их дальнейшим анализом и практическим разбором. Взгляд на себя со стороны помогает многим участникам тренинга переосмыслить свой коммуникативный инструментарий, от- 
рефлексировать собственные действия, развить навыки критического мышления, сформировать способности к трансцендентности - выхода за пределы собственного «Я» и возможности посмотреть на себя и собственные действия в качестве своеобразного «независимого» наблюдателя.

Но технологии не ограничиваются только видеозаписью происходящего на тренинге. Появились программы, позволяющие анализировать речь, голосовые модуляции, изменения выражения лица, движения и глаз и иные вербальные, невербальные и паравербальные сигналы, которые участники посылают друг другу во время тренингового процесса. Использование подобных технологий может резко повысить эффективность тренинга и будет способствовать главной его цели - развитию профессиональных компетенций участников.

Таким образом, в ситуации интенсивной плотной коммуникации, которой является социально-психологический тренинг, профессиональные компетенции и формируются у государственных гражданских служащих быстрее, и интериоризируются («присваиваются») ими осмысленно и генерализуются (используются за пределами тренинга) у них чаше, чем при использовании иных инструментов развития компетенций.

Вместе с тем, хотелось бы предостеречь от возможной эйфории при выборе социально-психологического тренинга как ключевого средства формирования и развития профессиональных компетенций у государственных гражданских служащих. Как и любого другого средства, у тренинга имеются определенные недостатки, о которых необходимо упомянуть и которые следует учитывать в практической деятельности. Прежде всего, речь идет об уровне квалификации лиц, организующих и проводящих тренинги, а также об их этической и социальной ответственности. Часто тренер уделяет более серьезное внимание отработке «техники» навыка, нежели формированию у участников внутреннего плана понимания смысла и специфики использования данного навыка. Нередко игры, задания и упражнения, используемые на тренинге, используются как «вещь в себе» без дальнейшей их рефлексии. Частью проблемы непрофессионализма или неэтичности тренера является «привязывание» тренером к себе участников тренинга, формирование у них эмоциональной и психологической зависимости от себя, других участников и самого тренинга.

Не менее острой является проблема содержания тренинга. Если взять за основу две основные цели любого социально-психологического тренинга - формирование навыков и эмоциональная «разрядка» для участников, то в настоящее время наблюдается явный перекос в сторону второй из них. Хотя эмоциональная разрядка очень важна и помогает участникам почувствовать себя в относительной психологической безопасности, раскрепоститься, убрать внутренние зажимы, непринужденно продуци- 
ровать и выдвигать новые идеи, все же тренинг, на котором не уделяется должное внимание отработке определенных навыков, никак не может способствовать развитию профессиональных компетенций, и, как следствие, повышению производительности труда.

Отдельно хочется сказать еще об одной проблеме, имеющей отношение к социально-психологическим тренингам. Она связана с неоправданным расширением представления о том, что это такое. Автору нередко приходилось сталкиваться с тем, что под тренингами понимаются минилекции, просмотры видеосюжетов, выступления профессиональных «гуру» перед массовыми аудиториями, которые жадно впитывают каждое слово «учителя», но при этом, конечно, речи о формировании профессиональных компетенций как совокупности знаний, умений и навыков не идет. Подобного рода «тренинги» формируют превратное представление о содержательной части и практической пользе от социально-психологических тренингов, привлекают в профессию некомпетентных, социально и личностно незрелых людей и различного рода шарлатанов, порождают негативные представления о социально-психологическом тренинге как у руководителей организаций, так и у потенциальных участников.

Подводя итоги, необходимо отметить, что проблема формирования и развития профессиональной компетентности имеет важное значение как для бизнеса и некоммерческой сферы, так и для государственной гражданской службы. В современной науке нет единого подхода к пониманию природы и содержанию профессиональной компетентности, что создает известные трудности не только для ее изучения, но и для практической оценки, формирования и развития конкретных профессиональных компетенций у исполнителей. Вместе с тем, можно выделить три основных направления исследований профессиональной компетентности: «поведенческое», во главу угла ставящее стереотипные поведенческие навыки исполнителей, позволяющие им эффективно решать рабочие задачи; «личностное», предлагающее учитывать ценности, мотивы, установки, социальные роли исполнителей, без которых не имеет смысла оценивать их конкретные знания, умения и навыки и «ситуативное», в основе которого лежит способность исполнителей адаптироваться к условиям сложной, динамичной и изменчивой рабочей среды. По нашему мнению, «ситуационное» направление (подход) является наиболее продуктивным для формирования и развития профессиональной компетентности государственных гражданских служащих.

Для формирования и развития профессиональных компетенций у государственных гражданских служащих органы власти имеют возможность использовать широкий ассортимент средств: организационных (корпоративных), управленческих и психологических. При этом важно, 
чтобы все средства формирования и развития профессиональных компетенций были систематизированы и согласованы между собой.

Наиболее эффективным средством формирования и развития профессиональных компетенций у государственных гражданских служащих, затрагивающим все компоненты компетентности в рамках «ситуационного» подхода является социально-психологический тренинг. Тренинг позволяет не только повысить уровень «стандартных» профессиональных знаний, умений и навыков государственных гражданских служащих, но и способствует развитию у них определенных качеств (например, критического и творческого мышления, способности к адаптации, общительности), позволяющих решать проблемы и задачи повышенной сложности. Помимо этого, социально-психологический тренинг повышает внутреннюю мотивацию государственных гражданских служащих к развитию своего профессионализма, что, в конечном итоге, неизбежно скажется и на повышении производительности их труда, и на уровне удовлетворенности потребителей государственных услуг, и на отношении граждан России к власти и ее представителям.

\section{СПИСОК ЛИТЕРАТУРЫ}

Адизес, И. (2007) Идеальный руководитель: Почему им нельзя стать и что из этого следует. М. : Альпина Бизнес Букс. 262 с.

Альбрехт, К. (2011) Социальный интеллект. Наука о навыках успешного взаимодействия с окружающими. М. : Бизнес Психологи. 301 с.

Барышникова, Е. И. (2013) Оценка персонала методом ассессментцентра. Лучшие HR-стратегии. М. : Манн, Иванов и Фербер. 255 с.

Бояцис, Р. (2008) Компетентный менеджер. Модель эффективной работы. М. : НIPPO. 352 с.

Горелова, Е. (2015) Навыки, которые помогут сделать карьеру в XXI веке // Ведомости. № 3801. 31 марта. URL: https://www.vedomosti.ru/ management/articles/2015/03/31/naviki-kotorie-pomogut-sdelat-kareru-vhhi-veke (дата обращения: 13.06.2017).

Горский, Д. А. (2013) Коммуникативная компетентность персонала как ключевой фактор эффективности компаний в условиях современного рынка // Высшее образование для XXI века: X Международная научная конференция. Москва. 14-16 ноября 2013 г.: Доклады и материалы. Симпозиум. Формирование коммуникативной компетентности /отв. ред. Р. Т. Мухаев. М. : Изд-во Моск. гуманит. ун-та. С. 24-30.

Дивненко, О. В., Горский, Д. А. (2017) Роль профессиональных компетенций сотрудников бизнес-структур в повышении производительности труда: психологический аспект // Вестник Национального института бизнеса. Вып. 28. Двадцать третья межвузовская научно-практическая кон- 
ференция по актуальным вопросам экономики, управления и права 20 марта 2017 г. М. : Издательство Московского гуманитарного университета. С. $148-154$.

Равен, Дж. (2002) Компетентность в современном обществе. Выявление, развитие и реализация. М. : Когито-центр. 396 с.

Равен, Дж. (2014) Компетентность, образование, профессиональное развитие, психология и социокибернетика // Вектор науки ТГУ. Серия: педагогика, психология. № 2 (17). С. 170-204.

Спенсер, Л., Спенсер, С. (2005) Компетенции на работе. М. : НIPPO. $384 \mathrm{c}$.

Дата поступления: 10.06.2017 2.

Горский Дмитрий Александрович - доцент кафедры теории рекламы и массовых коммуникаций Московского гуманитарного университета. Адрес: 111395, Россия, г. Москва, ул. Юности, д. 5. Тел.: +7 (499) 374-7159. Эл. адрес: dgorsky@inbox.ru

Gorskiy Dmitriy Aleksandrovich, Associate Professor, Department of the Theory of Advertising and Mass Communications, Moscow University for the Humanities. Postal address: 5, Yunosti St., Moscow, Russian Federation 111395. Tel.: + 7 (499) 374-71-59. E-mail: dgorsky@inbox.ru

\section{Для цитирования:}

Горский Д. А. Социально-психологический тренинг как средство формирования профессиональной компетентности государственных гражданских служащих [Электронный ресурс] // Научные труды Московского гуманитарного университета. 2017, № 3. URL: http://journals.mosgu.ru/trudy/article/view/497 (дата обращения: дд.мм.гг.). DOI: $10.17805 /$ trudy.2017.3.3 